\title{
OPTIMIZED ROUTING OF TRUCKS FOR INSTITUTIONAL SOLID WASTE COLLECTION IN KUMASI, GHANA
}

\author{
Alhassan Sulemana ${ }^{1, *}$, Emmanuel Amponsah Donkor ${ }^{2}$, Eric Kwabena Forkuo ${ }^{3}$, Juliet \\ Asantewaa ${ }^{1}$, Isabella N.A. Ankrah ${ }^{1}$ and Abdul Muhaymin O. Musah ${ }^{1}$ \\ ${ }^{1}$ Department of Environmental Science, Kwame Nkrumah University of Science and Technology, Private Mail Bag, University Post Office, \\ Kumasi, Ghana \\ ${ }^{2}$ Department of Civil Engineering, Kwame Nkrumah University of Science and Technology, Private Mail Bag, University Post Office, \\ Kumasi, Ghana \\ ${ }^{3}$ Department of Geomatic Engineering, Kwame Nkrumah University of Science and Technology, Private Mail Bag, University Post \\ Office, Kumasi, Ghana
}

Article Info:

Received:

16 July 2019

Revised:

31 October 2019

Accepted:

08 November 2019

Available online:

28 January 2020

Keywords:

Solid waste collection

Geographic information system

Vehicle routing problem solver

Route optimization

Network analyst extension

\section{ABSTRACT}

Solid waste collection constitutes $60-80 \%$ of the total solid waste management cost. Reduction of solid waste collection cost can be achieved through route optimization in a geographic information system (GIS) environment. The purpose of this study was to generate optimized routes for solid waste collection on Kwame Nkrumah University of Science and Technology campus in Kumasi, Ghana. The study modelled the existing routes for a complete collection cycle using travel time criteria and generated optimized routes for same using an ArcGIS software. Validation of the optimized outcome (travel distance and travel time) was done by subjecting the solid waste collection trucks to the optimized routes. The results from the study showed significant reduction in total travel time from $1,000.75$ mins to 855.70 mins for existing and optimized routes respectively, translating into saving of $14.5 \%$. Total travel distance significantly reduced from $367.30 \mathrm{~km}$ to $334.20 \mathrm{~km}$ for existing and optimized routes respectively, representing saving of $9.0 \%$. Significant savings in travel time and travel distance have implications on reduction of fuel and maintenance cost of institutional solid waste collection trucks. The results indicate that the application of GIS-based route optimization in solid waste collection can provide significant improvement in reduction of operating cost.

\section{INTRODUCTION}

The rapid increase in human population, switch from traditional agricultural methods to industrialization and technological advancement have resulted in increased generation of solid waste. Management of solid waste is a major challenge, especially to developing countries partly due to lack of effective and adequate management systems. Solid waste management is a discipline that involves processes including; control of the waste generated, collection, processing, reuse and recovery and finally its disposal (Diaz et al., 2005; Tchobanoglous et al., 1993). Collection of waste is recognized as one of the most essential stages in the solid waste management process (Coffey and Coad, 2010). Efficient waste collection involves the regular collection, cleanup and transportation of solid waste to treatment or disposal sites. The process is designed and operated in an integrated way such that all aspects are selected taking into consideration: (1) Type of collec- tion service production; (2) Type of collection system and equipment used as well as associated labour; (3) Analysis of collection systems; and (4) General methodology in collection route setting (Tchobanoglous et al., 1993).

The cost of solid waste collection is reported by previous studies to constitute about $60-80 \%$ of the total budget of solid waste management (Ansari and Pakrou, 2015; Beliën et al., 2014; Sulemana et al., 2018). According to Li et al. (2014) and Tavares et al. (2009), the huge expenditure on solid waste collection is warranted from the high cost of fuel and maintenance since the collection process involves extensive use of trucks. There is a necessity to cut down collection cost by practitioners and one of the most effective means indicated by previous studies is through route optimization. Routing involves scheduling and defining routes travelled by trucks during the solid waste collection process (Sulemana et al., 2018). Poor and expensive collection systems can come about when routes are selected without using scientific or technological methods (Tavares et al.,
* Corresponding author

Alhassan Sulemana

email: sulemanaalhassan@knust.edu.gh
Detritus / Volume 09 - 2020 / pages 50-58

https://doi.org/10.31025/2611-4135/2020.13896

(c) 2019 Cisa Publisher. Open access article under CC BY-NC-ND license 
2009). Previously, the determination of routes for collection trucks was left to the drivers' discretion (Beliën et al., 2014). Such a state has often engendered remarkably high solid waste collection cost. Therefore, there is the need to scientifically generate optimized routes to cut down time and distance travelled by trucks and operating cost.

Route optimization involves scheduling collection trucks to visit all waste collection points in a defined path that reduces the total travel cost through reduction in fuel consumption and operating time (Chalkias and Lasaridi, 2009). This can effectively be achieved through significant savings in travel time and distance. Several studies have been conducted on the use of geographic information system (GIS) applications as a tool for municipal solid waste management (Ristic et al., 2015; Sulemana et al., 2019; Zsigraiova et al., 2013). GIS technology is a widely used decision support system which provides an advanced modelling framework for decision makers in order to analyze and simulate various spatial problems (Chalkias and Lasaridi, 2009). Various studies have been done optimizing solid waste collection in local authorities within GIS environment with dearth information on institutional setting. This study therefore attempts to answer the question: How does optimized routes contribute to reduction of operating cost through savings in travel time and fuel consumption? In this regard, this study sought to optimize nineteen routes for solid waste collection on the campus of a selected university in developing country setting. Implementation of the outcome of route optimization can significantly contribute to operating cost reduction in solid waste collection.

\section{METHODOLOGY}

\subsection{Description of study area}

The study was conducted at Kwame Nkrumah University of Science and Technology (KNUST) campus, Kumasi, situated in the Oforikrom Municipal Assembly of the Ashanti Region of Ghana (Figure 1). KNUST is a public educational institution established in 1950. It is situated approximately on a sixteen square-kilometer sub-urban area and located around Latitude $6^{\circ} 41^{\prime} 5.67^{\prime \prime} \mathrm{N}$ and Longitude $1^{\circ} 34^{\prime} 13.87^{\prime \prime} \mathrm{W}$. The institution has a current student population of 56,403 , teaching staff population of 1,074 and non-teaching staff population of 2,578 . The campus is divided into a faculty area (housing the six colleges), a residential area (constituting the halls, hostels and staff bungalows) and commercial area. The collection of MSW on KNUST campus is managed by the Environmental Quality Unit of the university.

The solid waste collection systems practiced in KNUST include pegged bins collection, small bins collection and communal bins collection with bin sizes of $120 / 240 \mathrm{~L}$, $240 \mathrm{~L}$ and $12 \mathrm{~m}^{3}$ respectively. The pegged and small bins collections are done using compactor trucks (12 tons capacity) while the communal bins are collected using skip trucks ( $12 \mathrm{~m}^{3}$ capacity). The pegged and small bins collections service five operational sites (routes) each in a cycle (i.e. $P_{1}-P_{5} \& S_{1}-S_{5}$ respectively) whereas the communal bins service nine operational sites in a cycle (i.e. $\mathrm{C}_{1}-\mathrm{C}_{9}$ ). The university has four compactors and three skip trucks with two of each truck type functioning at the time of data collection. Collection of MSW on KNUST campus from the

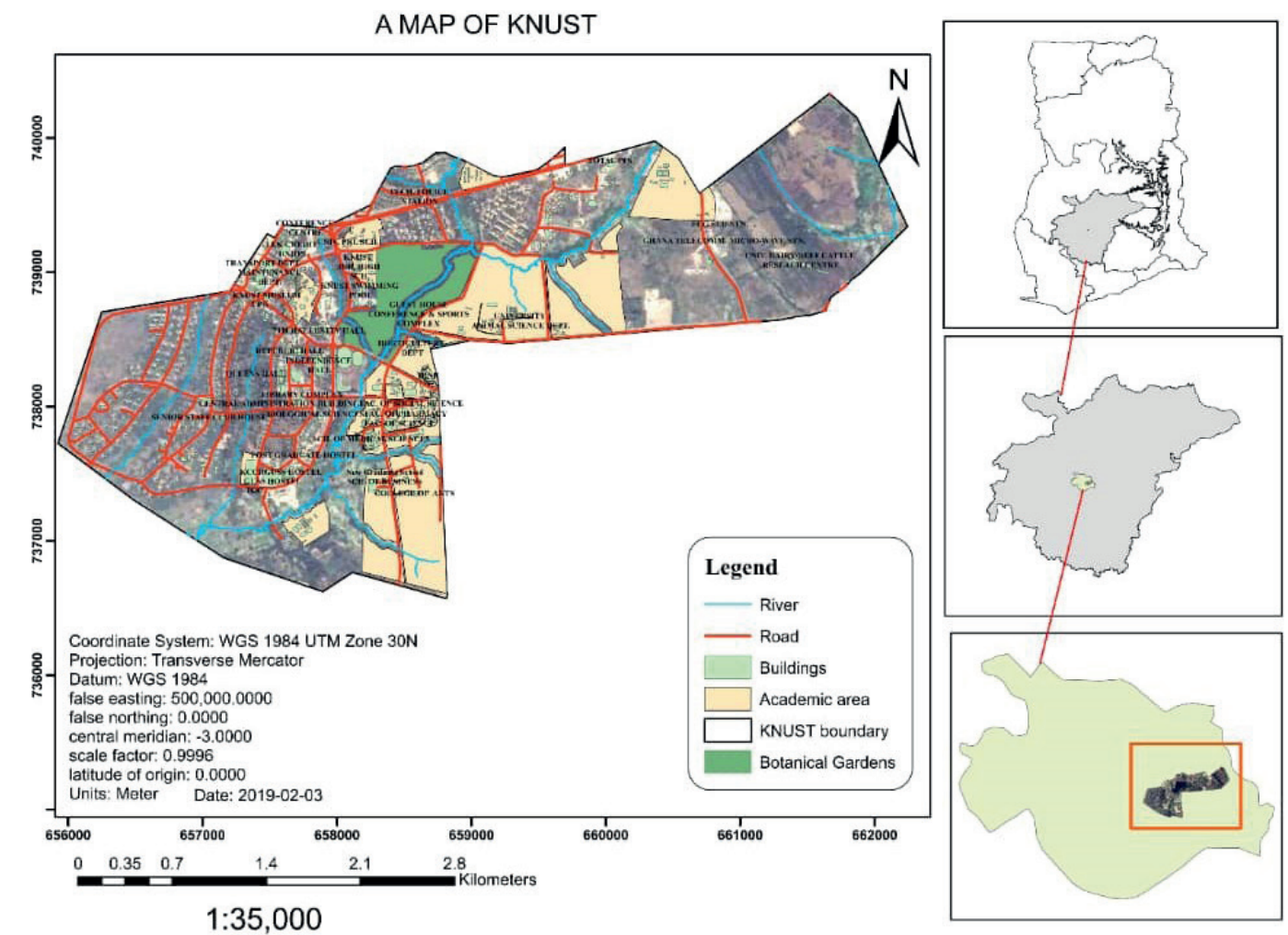

FIGURE 1: Map of KNUST campus showing road networks. 
faculty, residential and commercial areas is done six days in a week (from Mondays to Saturdays). The MSW are collected without any segregation at source of generation. During collection, drivers are assigned to specific orders (collection points) and the drivers assigned to specified collection sites apply their discretion on the routes used. Each compactor truck has a collection crew, consisting of a driver and about six accompanying janitors whiles the skip trucks are operated by two people, i.e. the driver and his janitor.

\subsection{System requirements and design for optimized routing}

System requirements for the study were grouped into functional and non-functional requirements. Functional requirements constituted the input elements of the optimization system. These included the orders (collection points), depots (landfill site and transport yard) and road network dataset. Road network dataset consisted of a compilation of the shapefiles of all roads within the study area. The non-spatial road attributes were established through field observation and measurement. The non-functional requirements played an auxiliary role in the optimization system. These were the operational, technical and transitional aspects of the study that were essential in performing the analysis as indicated by O'Connor (2013). A computer with Microsoft Windows 8.1 operating system served the technical role. Other specifications of the computer included a $2.0 \mathrm{GHz}$ processor and $8 \mathrm{~GB}$ RAM for boosted performance. The technical services of a 10.5 version ESRI ArcGIS software equipped with the latest features for the establishment of both existing and optimal route models was used.

A thorough understanding of the operation of the ArcGIS software extension was required to structure the components precisely and to accurately design, construct and execute the network analysis using the Vehicle Routing Problem (VRP) solver. The non-functional variables (transitional data) used in the study construction were in geodatabase format; compactible with the 10.5 version of ArcGIS software. Microsoft Excel and Word 2016 formats constituted the construction of tables and guidance documents for non-functional transitional purposes. The entire system was designed from analyzing the requirements and structured to accommodate the system's principal functional and non-functional components. The VRP solver of ArcGIS software used functional requirement inputs and parameters of travel time and distance to set up and construct optimized routes with optimal sequencing (Figure 2). Additional layers such as traffic lights, right turn, round-about, speed rams, pedestrian crossings and one-way roads were inputted to estimate time delays and restrictions on the roads. With all factors accounted for, optimized routes were generated accordingly. Route accuracy evaluation was carried out by plotting generated routes on Open Street Map and any new parameter identified and necessary adjustments re-entered into the optimization system.

\subsection{Mapping and data collection}

Detailed spatial information was required to generate the optimized routes. The spatial information comprised of the geographical background of the study area and the

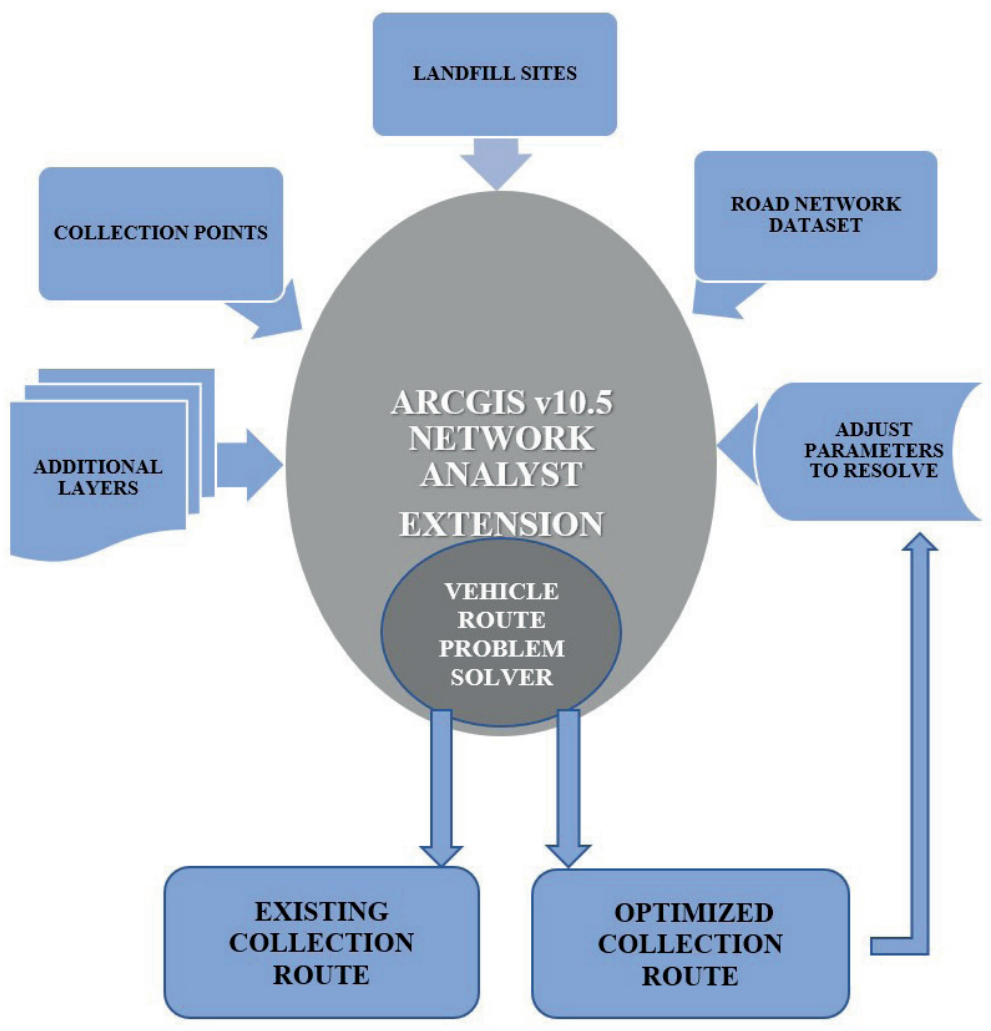

FIGURE 2: System design for route optimization in GIS environment. 
spatial data related to the waste collection procedure. The static and dynamic data for the existing collection system were obtained from the KNUST Environmental Quality Unit. This consisted of: the population density; road network and attributes; position, number and type of the waste collection bins; routing system used by trucks; capacity and other characteristics of the collection trucks; and the geographic location, boarders and other characteristics of KNUST relevant to waste collection. The following data were generated for the optimization of collection routes: the boundary, detailed plan, road networks and road class information (traffic volume and road restrictions) of study area. Satellite image of KNUST was derived from Google Earth and the collection points of waste were obtained from field work using a GPS device. The schedule for waste collection in all the operational sites for the existing collection routes were obtained from the KNUST Environmental Quality Unit.

To optimize the collection routes, ESRI ArcGIS was used to generate a spatial geodatabase. This ensured congeniality with data obtained from the waste management section of the institution and access to many network analysis routines available from the software as reported by Chalkias \& Lasaridi (2009). The road network's background spatial data for existing waste collection routes were obtained and updated. Non-spatial (attribute) data considered include road name, type, slope, collection time and average speed of vehicles. The road attributes such as traffic marks, topographic condition and spatial restrictions (turn restrictions) were noted and used to efficiently model conditions similar to that of the real-world road network conditions. The spatial database used are summarized in Table 1.

\subsection{Optimization and validation of optimized waste collection routes}

Collection points and landfill sites' coordinates were taken using GPS device in a routine day-to-day collection process in the study area. With all variables in place, existing routes of the study area were generated on the digital map. A network dataset of roads was constructed to ensure that all streets were connected at junctions. Time delay variables such as traffic lights, speed rams, turns and pedestrian crossings were inputted for a better estimation of any impedance encountered during the collection process. Table 2 presents the attributes of the roads, containers, vehicles and delay parameters. These delay variables were allocated appropriate units in second(s). The route optimization process was based on travel time but travel
TABLE 1: Summary of the spatial database used.

\begin{tabular}{|c|c|c|}
\hline Spatial Data & Type & Geometry \\
\hline Road Network & Vector & Line \\
\hline Waste Bins & Vector & Point \\
\hline KNUST Urban plan & Vector & Polygon \\
\hline Existing Collection Routes & Vector & Line \\
\hline Street Address & Tabular & - \\
\hline $\begin{array}{l}\text { Road Network Attributes and } \\
\text { Restrictions }\end{array}$ & Tabular & - \\
\hline Satellite image of KNUST & Raster & - \\
\hline
\end{tabular}

distance was also estimated. These travel time and travel distance were measured in "seconds" (sec) and "kilometers" $(\mathrm{km})$ respectively in the VRP Solver interface of the ArcGIS software. The VRP Solver constructed routes with several iterations made until optimized collection routes were identified. Comparisons of the identified optimal routes were made against the existing routes and tested on the ground to determine the credibility of the routes generated.

\subsection{Data analysis}

Data obtained from the existing and optimized situations were compared. Data in the form of time spent and distance travelled were measured for both situations. The data measured were tested using a paired sample t-test at a significance level of $5 \%$. From the comparison, the difference in savings were expressed in terms of percentage.

\section{RESULTS AND DISCUSSION}

\subsection{Existing and optimized routes for solid waste collection}

When the solid waste collection trucks were subjected to the optimized routes, reductions in travel distance and travel time were observed in the operational sites of the study area. Of the nineteen routes optimized, one randomly selected route, each from small, pegged and communal bins collection services $\left(\mathrm{S}_{3}, \mathrm{P}_{2}\right.$ and $\mathrm{C}_{8}$ respectively) are presented in detail in Figures 3-5 and the rest have been included in the supplementary material. In the operational site $\mathrm{S}_{3}$ for instance, travel distance and travel time reduced from 19.70 to $16.40 \mathrm{~km}$ and 67.40 to $44.97 \mathrm{~min}$ respectively (Figure 3 ). These converted into savings of $16.8 \%$ and $33.5 \%$ for travel distance and travel time respectively. The operational site $\mathrm{P}_{2}$ recorded reductions from 23.00 to $18.50 \mathrm{~km}$

TABLE 2: Determination of attributes of roads, containers, delays and vehicles.

\begin{tabular}{|c|c|c|}
\hline Item & Attributes & Determination \\
\hline Roads & Names, junctions, left turns, right turns and round-about & $\begin{array}{l}\text { Information obtained from field visits with support from the } \\
\text { Environmental Quality Unit of the University }\end{array}$ \\
\hline Containers & Type, volume, location and lifting frequency & $\begin{array}{l}\text { Information obtained from field visits with support from the } \\
\text { Environmental Quality Unit of the University }\end{array}$ \\
\hline Vehicles & Type, capacity, containers serviced and routes used & $\begin{array}{l}\text { Information of the attributes were obtained from the Environ- } \\
\text { mental Quality Unit of the University }\end{array}$ \\
\hline Delays and impediments & $\begin{array}{l}\text { Traffic light, peed rumps, right-turns, round-about, one-way } \\
\text { traffic, etc. }\end{array}$ & Information of the attributes were obtained from field visits \\
\hline
\end{tabular}


and 76.20 to $58.15 \mathrm{~min}$ for travel distance and travel time respectively (Figure 4), translating into respective savings of $19.6 \%$ and $23.7 \%$. At operational site $\mathrm{C}_{8}$, reductions for travel distance and travel time were recorded as 23.00 to $20.00 \mathrm{~km}$ and 48.62 to $44.20 \mathrm{~min}$ (Figure 5), translating into savings of $13.0 \%$ and $9.1 \%$, respectively.

The optimized routes generated were the shortest possible routes in terms of travel time criteria. This resulted in reduced travel times with savings recorded in all operational sites for the three collection systems (Table 3). Similar findings were reported by Sulemana et al. (2019) when they studied into the effects of optimal routing on travel distance, travel time and fuel consumption of waste collection trucks in three selected local authorities in Ghana. The optimization system considered road network impedances and restrictions such as traffic light, right turn, round-about, speed rams, pedestrian crossings and one-way road to generate the optimized routes which were time dependent. Although time criterion was used for the optimization, trav- el distances reduced in the collection systems except communal bins where optimized distances were greater than the existing distances. In such places, the quickest route, taking road impedances and restrictions into consideration were longer in terms of distance. Generally, travel distance reduced when trucks used the optimized routes.

The findings of this study are consistent with previous studies that applied GIS-based route optimization. Apaydin \& Gonullu (2007) used route optimization to collect solid waste in Trabzon, Turkey and achieved reductions of $4-59 \%$ for distance and $14-65 \%$ for time. GIS was also used by Zsigraiova et al. (2013) to define new collection schedule with reductions of $62 \%$ for the total spent time, $43 \%$ for the fuel consumption and $40 \%$ for emitted pollutants and total cost savings of $57 \%$ per year. This indicates that the application of route optimization has positive implications on fuel consumption of trucks and environmental conservation. Other previous studies have also reported reduced travel distance and travel time through

TABLE 3: Travel distance and travel time recorded on the three collection systems.

\begin{tabular}{|c|c|c|c|c|c|c|}
\hline \multirow{2}{*}{$\begin{array}{l}\text { Collection } \\
\text { Systems }\end{array}$} & \multicolumn{3}{|c|}{ Travel Distance (km) } & \multicolumn{3}{|c|}{ Travel Time (min) } \\
\hline & Existing Routes & Optimized Routes & Savings & Existing Routes & Optimized Routes & Savings \\
\hline Pegged Bins & 100.20 & 86.30 & 13.90 & 318.45 & 262.20 & 56.25 \\
\hline Smaller Bins & 104.30 & 84.30 & 20.00 & 326.00 & 259.20 & 66.80 \\
\hline Communal Bins & 162.80 & 163.60 & -0.80 & 356.30 & 334.30 & 22.00 \\
\hline All Systems & 367.30 & 334.20 & 33.10 & $1,000.75$ & 855.70 & 145.05 \\
\hline
\end{tabular}
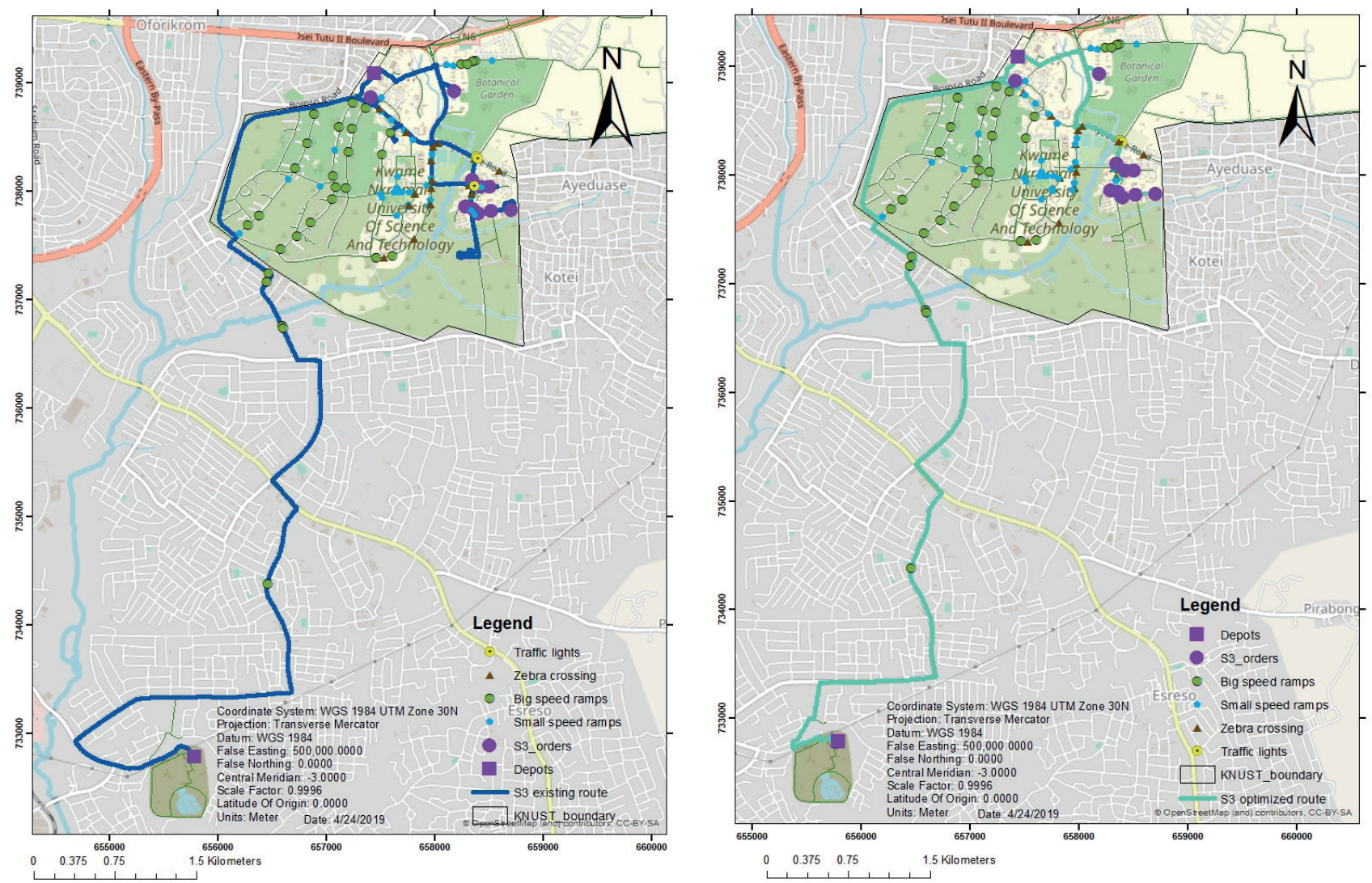

FIGURE 3: Existing and optimized routes for site $\mathrm{S}_{3}$. 

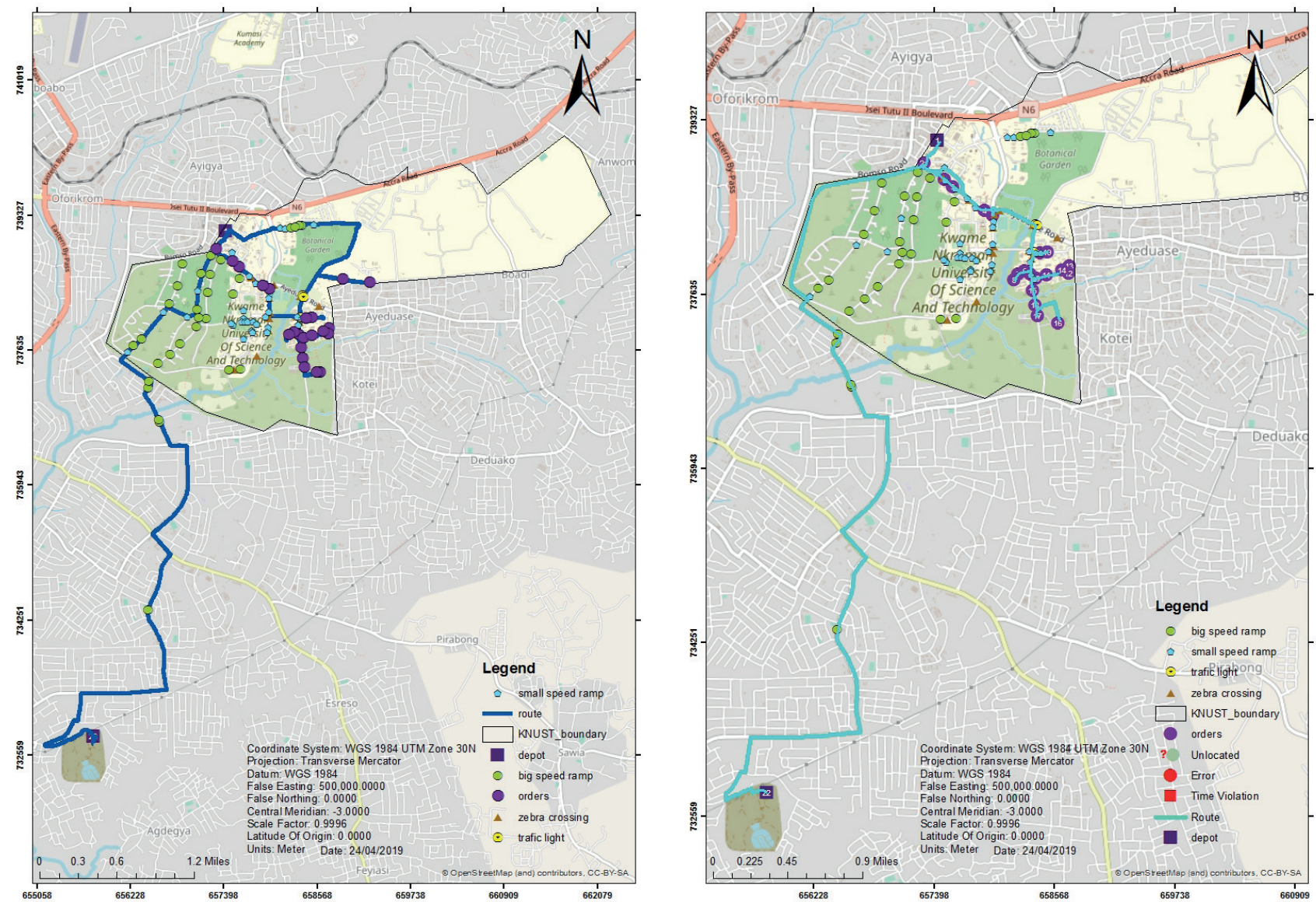

FIGURE 4: Existing and optimized routes for site $\mathrm{P}_{2}$.
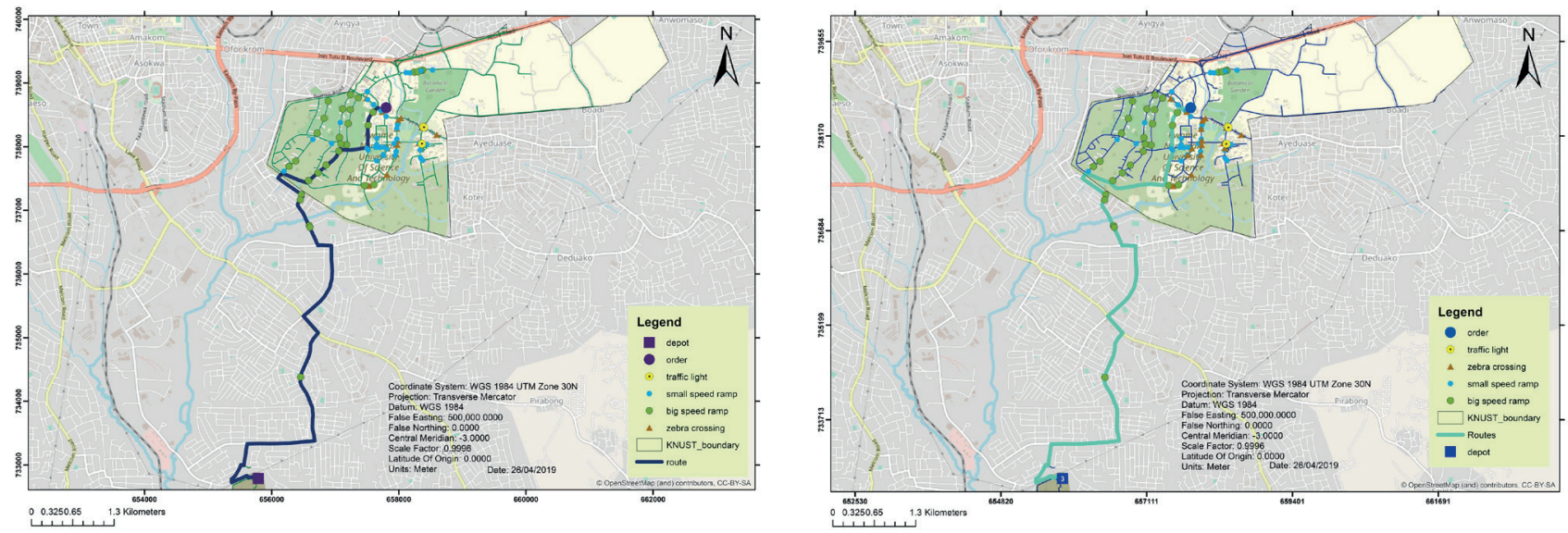

FIGURE 5: Existing and optimized routes for site $\mathrm{C}_{8}$.

route optimization (Knobe et al., 2015; Sulemana et al., 2018; Velumani, 2013).

\subsection{Travel distance on existing and optimized routes}

Pegged bins and small bins recorded relative reductions in travel distance for the optimized routes by 13.90 $\mathrm{km}$ and $20.00 \mathrm{~km}$ respectively with communal bins collection system recording an increase in travel distance for optimized routes by $0.80 \mathrm{~km}$ (Figure 6 ). When all collection systems were combined, travel distance for optimized routes relatively reduced by $33.10 \mathrm{~km}$, translating into saving of $9.0 \%$. Significant reduction in travel distance was recorded in most of the operational sites although the system optimization was done based on travel time criteria. Comparison of optimized distance with existing distance showed significant differences for pegged bins ( $p=0.018)$, small bins $(p=0.041)$ and all collection systems combined $(p=0.009)$, but not communal bins $(p=0.834)$ as displayed in Tables 4-7.

Significant reductions in travel distance can be attribut- 
TABLE 4: Paired samples t-test for travel distance and time for all collection systems.

\begin{tabular}{|c|c|c|c|c|c|c|c|c|c|}
\hline & & \multicolumn{5}{|c|}{ Paired Differences } & \multirow{3}{*}{$\mathbf{t}$} & \multirow{3}{*}{ df } & \multirow{3}{*}{$\begin{array}{c}\text { Sig. } \\
\text { (2-tailed) }\end{array}$} \\
\hline & & \multirow{2}{*}{ Mean } & \multirow{2}{*}{$\begin{array}{c}\text { Std. } \\
\text { Deviation }\end{array}$} & \multirow{2}{*}{$\begin{array}{c}\text { Std. } \\
\text { Error Mean }\end{array}$} & \multicolumn{2}{|c|}{ 95\% Confidence Interval } & & & \\
\hline & & & & & Lower & Upper & & & \\
\hline Pair 1 & $\begin{array}{l}\text { Existing } \\
\text { distance - opti- } \\
\text { mized distance }\end{array}$ & 2.0821 & 3.3226 & .7623 & .4807 & 3.6835 & 2.732 & 18 & .009 \\
\hline Pair 2 & $\begin{array}{l}\text { Existing time- } \\
\text { optimized time }\end{array}$ & 429.8420 & 423.0970 & 97.0650 & 225.9160 & 633.7680 & 4.428 & 18 & .000 \\
\hline
\end{tabular}

$t=t$-statistic value,$d f=$ degrees of freedom, sig. $=p$-value, std. $=$ standard

ed to the effective sequencing of service orders by the GIS-based route optimization system. This generated optimized routes with reduced distances as indicated by 0 'Connor (2013) and Sulemana et al. (2019) in their studies into route optimization using GIS-based approaches. This finding is supported by a study undertaken by Chalkias and Lasaridi (2009) which applied GIS-based optimization system to reduce travel distance, saving 5.5\% in the Municipality of Nikea, Athens, Greece. Malakahmad et al. (2014) further used route optimization to obtain a $22.0 \%$ length minimization in routes. Travel distance not being significant (Table $7)$ in three sites of the communal collection systems $\left(C_{2}\right.$ $\mathrm{C}_{3}$ and $\mathrm{C}_{6}$ ) serves as a testament to further indicate that travel distance is not a good criterion to effectively predict the operating cost of solid waste collection. This resulted from the fact that trucks spent comparatively shorter time on longer optimized routes in terms of distance due to high impedances and time delay constraints on shorter distances. These delay constraints include: speed ramps, number of turns, zebra crossings, traffic flows, etc. It is on this basis that travel distance does not prove a viable criterion for route optimization as reported by Kinobe et al. (2015) and Sulemana et al. (2019).

\subsection{Travel time on existing and optimized routes}

Pegged bins, communal bins, small bins and all collection systems combined recorded relative reduction each in travel time for the optimized routes by 56.25, 22.00, 66.80 and 145.05 min respectively (Figure 7). Significant reduction in travel time was recorded in each of the collection systems in the study area: pegged bins $(p=0.031)$, communal bins $(p=0.003)$, small bins $(p=0.024)$ and all collection systems $(p<0.001)$ when optimized travel time was compared with existing travel time (Tables 4-7). The system took into consideration the shortest distance to orders, taking account of road network impedances and time constraints. Significant differences in travel time were recorded for all collection systems (smaller bins, pegged bins and communal bins) when the trucks were subjected to the optimized routes. This resulted in reduced travel time for all collection systems.

Previous studies such as Ansari and Pakrou (2015) used GIS-based route optimization to obtain a travel time saving of $60.0 \%$ in Tabriz City, Iran. A similar study was conducted by Sallem and Rouis (2017) which yielded a travel time saving of $5.0 \%$ in optimization of household waste collection route in El Bousten District, Tunisia. It is

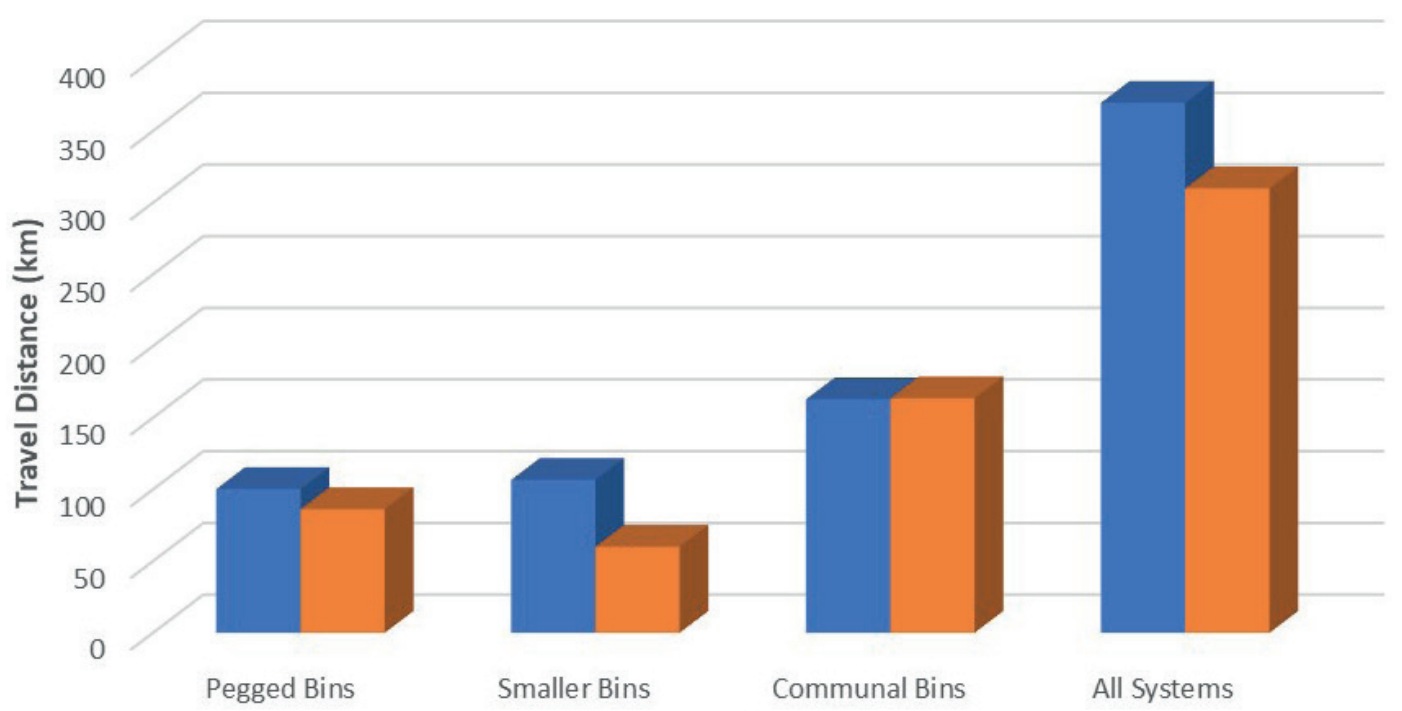

Collection Systems

- Existing Route $\quad$ Optimized Route

FIGURE 6: Mean travel distance on existing and optimized routes. 
TABLE 5: Paired samples t-test for travel distance and time for small bins collection system.

\begin{tabular}{|c|c|c|c|c|c|c|c|c|c|}
\hline & & \multicolumn{5}{|c|}{ Paired Differences } & \multirow{3}{*}{$\mathrm{t}$} & \multirow{3}{*}{ df } & \multirow{3}{*}{$\begin{array}{c}\text { Sig. } \\
\text { (2-tailed) }\end{array}$} \\
\hline & & \multirow{2}{*}{ Mean } & \multirow{2}{*}{$\begin{array}{c}\text { Std. } \\
\text { Deviation }\end{array}$} & \multirow{2}{*}{$\begin{array}{c}\text { Std. } \\
\text { Error Mean }\end{array}$} & \multicolumn{2}{|c|}{ 95\% Confidence Interval } & & & \\
\hline & & & & & Lower & Upper & & & \\
\hline Pair 1 & $\begin{array}{l}\text { Existing } \\
\text { distance - opti- } \\
\text { mized distance }\end{array}$ & 4.0000 & 3.0125 & 1.3472 & .2595 & 7.7405 & 2.969 & 4 & .041 \\
\hline Pair 2 & $\begin{array}{l}\text { Existing time- } \\
\text { optimized time }\end{array}$ & 801.600 & 506.074 & 226.323 & 173.226 & 1429.974 & 3.542 & 4 & .024 \\
\hline
\end{tabular}

$t=t$-statistic value,$d f=$ degrees of freedom, sig. $=p$-value, std. $=$ standard

TABLE 6: Paired samples t-test for distance and time for pegged bins collection system.

\begin{tabular}{|c|c|c|c|c|c|c|c|c|c|}
\hline & & \multicolumn{5}{|c|}{ Paired Differences } & \multirow{3}{*}{$t$} & \multirow{3}{*}{ df } & \multirow{3}{*}{$\begin{array}{c}\text { Sig. } \\
\text { (2-tailed) }\end{array}$} \\
\hline & & \multirow{2}{*}{ Mean } & \multirow{2}{*}{$\begin{array}{c}\text { Std. } \\
\text { Deviation }\end{array}$} & \multirow{2}{*}{$\begin{array}{c}\text { Std. } \\
\text { Error Mean }\end{array}$} & \multicolumn{2}{|c|}{ 95\% Confidence Interval } & & & \\
\hline & & & & & Lower & Upper & & & \\
\hline Pair 1 & $\begin{array}{l}\text { Existing } \\
\text { distance - opti- } \\
\text { mized distance }\end{array}$ & 2.8400 & 1.6273 & .7277 & .8195 & 4.8605 & 3.903 & 4 & .018 \\
\hline Pair 2 & $\begin{array}{l}\text { Existing time- } \\
\text { optimized time }\end{array}$ & 567.600 & 387.292 & 173.202 & 86.714 & 1048.486 & 3.277 & 4 & .031 \\
\hline
\end{tabular}

$t=t$-statistic value, $d f=$ degrees of freedom, sig. $=p$-value, std. $=$ standard

TABLE 7: Paired samples t-test for distance and time for communal bins collection systems.

\begin{tabular}{|c|c|c|c|c|c|c|c|c|c|}
\hline & & \multicolumn{5}{|c|}{ Paired Differences } & \multirow{3}{*}{$t$} & \multirow{3}{*}{ df } & \multirow{3}{*}{$\begin{array}{c}\text { Sig. } \\
\text { (2-tailed) }\end{array}$} \\
\hline & & \multirow{2}{*}{ Mean } & \multirow{2}{*}{$\begin{array}{c}\text { Std. } \\
\text { Deviation }\end{array}$} & \multirow{2}{*}{$\begin{array}{c}\text { Std. } \\
\text { Error Mean }\end{array}$} & \multicolumn{2}{|c|}{$95 \%$ Confidence Interval } & & & \\
\hline & & & & & Lower & Upper & & & \\
\hline Pair 1 & $\begin{array}{l}\text { Existing } \\
\text { distance - opti- } \\
\text { mized distance }\end{array}$ & -.0933 & 1.2961 & .4320 & -1.0896 & .9029 & -.216 & 8 & .834 \\
\hline Pair 2 & $\begin{array}{l}\text { Existing time- } \\
\text { optimized time }\end{array}$ & 146.778 & 106.504 & 35.501 & 64.911 & 228.644 & 4.134 & 8 & .003 \\
\hline
\end{tabular}

$t=t$-statistic value,$d f=$ degrees of freedom, sig. $=p$-value, std. $=$ standard

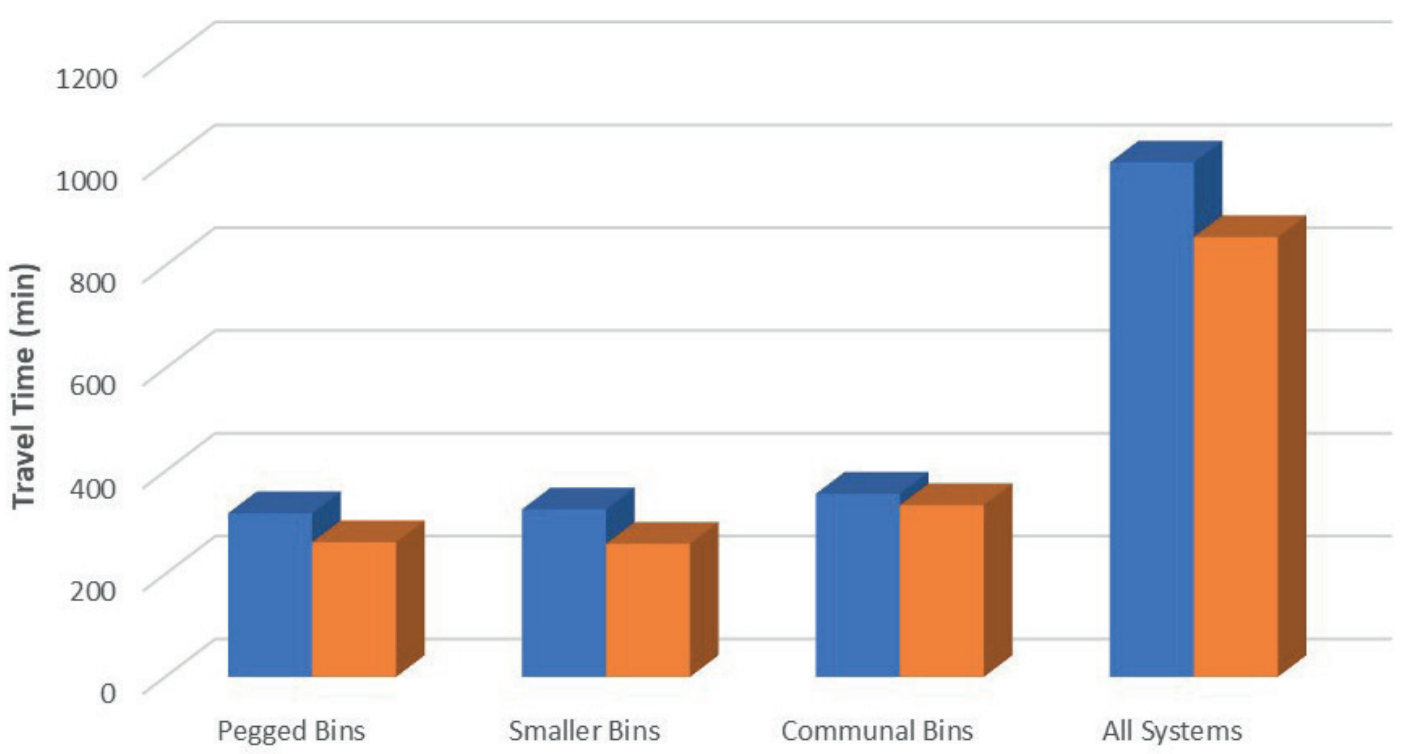

Collection Systems

Existing Route aptimized Route

FIGURE 7: Mean travel time on existing and optimized routes. 
on this basis that travel time proved the main criterion for route optimization in this study due to the fact that travel time is directly proportional to operational time with implication on cost (Kinobe et al., 2015). This supports the claim of the possibility of increasing operational coverage of waste collection and get more work done due to optimal time usage (Sulemana et al., 2019). Findings from this study indicate that the longer a truck travels on a specific route, more distance is covered, resulting in more working time as well as fuel and maintenance cost. A reduction in travel time translates into less fuel consumption and less period for servicing trucks hence, associated cost reduction (Chalkias \& Lasaridi, 2009). This is consistent with previous studies that applied route optimization in a GIS environment (Risti'c et al., 2015; Sulemana et al., 2019; Tavares et al., 2009).

\section{CONCLUSIONS}

The study used route optimization to significantly reduce travel time and travel distance of solid waste collection on KNUST campus. Various geographical data (road networks, collection points, road limitations, etc.) were used in this method with Network Analyst extension of ArcGIS software. The road network analysis tool of the VRP solver in GIS environment facilitated the generation of routes with relatively reduced travel distance and travel time. The results from the study showed reduction in total travel time from $1,000.75$ mins to 855.70 mins for existing and optimized routes respectively, representing saving of $14.5 \%$. Total travel distance reduced from $367.30 \mathrm{~km}$ to $334.20 \mathrm{~km}$ for existing and optimized routes respectively, representing saving of $9.0 \%$. The results show that, the optimal routes generated were more efficient in terms of travel distance and travel time. Significant savings made for all the various collection systems on KNUST campus in relation to travel distance and travel time supports the hypothesis that, optimal routes reduce solid waste collection operating cost through significant savings in travel time, thereby reducing fuel consumption. The optimized routes were not previously implemented and hence are recommended for use. This study is therefore not only a theoretical one, but it has a clear benefit, which ensures an optimization of the waste collection in KNUST. Route optimization should therefore be considered in policy provisions associated with operating cost reduction in relation to solid waste collection. There is the need to broaden the scope of route optimization in future studies to establish the effects of daily and seasonal variations on the optimal outcomes. Further study should also aim at developing decision support systems related to route optimization which are more user friendly for easy adoption and usage by practitioners.

\section{REFERENCES}

Addo, I. B., Adei, D., and Acheampong, E. O. (2015). Solid Waste Management and Its Health Implications on the Dwellers of Kumasi Metropolis, Ghana. Current Research Journal of Social Sciences, 7(3), 81-93.

Ansari, M., and Pakrou, S. (2015). Optimization of MSW collection routes using GIS (case study: Tabriz City). Current World Environment, 10(1), 882-890. https://doi.org/10.12944/CWE.10.Special-Issue1.107

Apaydin, O., and Gonullu, M. T. (2007). Route optimization for solid waste collection: Trabzon (Turkey) case study. Global NEST Journal, 9(1), 6-11.

Beliën, J., De Boeck, L., and Van Ackere, J. (2014). Municipal solid waste collection and management problems: A literature review. Transportation Science, 48(1), 78-102. https://doi.org/10.1287/ trsc. 1120.0448

Chalkias, C., and Lasaridi, K. (2009). A GIS based model for the optimisation of municipal solid waste collection: the case study of Nikea, Athens, Greece. WSEAS Transactions on Environment and Development, 5(10), 640-650.

Chalkias, C., and Lasaridi, K. (2009). Optimizing municipal solid waste collection using GIS. 5th International Conference on Energy, Environment, Ecosystems and Sustainable Development/2nd International Conference on Landscape Architecture, Greece. In: Proceedings of Energy, Environment, Ecosystems, Development and, Landscape Architecture, 45-50.

Coffey, M., and Coad, A. (2010). Collection of municipal solid waste in developing countries. UN-HABITAT, Malta.

Diaz, L. F., Savage, G. M., and Eggerth, L. L. (2005). Solid Waste Management. (L. L. Eggerth, G. M. Savage, and L. F. Diaz, Eds.), Cities (Vol. 1). https://doi.org/10.1002/9780470999677

Kinobe, J. R., Bosona, T., Gebresenbet, G., Niwagaba, C. B., and Vinner as, B. (2015). Optimization of waste collection and disposal in Kampala city. Habitat International, 49, 126-137.

Li, C.-Z., Zhang, Y., Liu, Z.-H., Meng, X., and Du, J. (2014). Optimization of MSW collection routing system to reduce fuel consumption and pollutant emissions. Nature Environment and Pollution Technology, 13(1), 177-184.

Malakahmad, A., Bakri, P., Mokhtar, M. R., and Khalil, N. (2014). Solid waste collection routes optimization via GIS techniques in Ipoh city , Malaysia. Procedia Engineering, 77(December 2013), 20-27. https://doi.org/10.1016/j.proeng.2014.07.023

O'Connor, D. L. (2013). Solid waste collection vehicle route optimization for the city of Redlands, California. University of Redlands.

Risti'c, G., Djordjevi'c, A., Hristov, S., Umǐcevi'c, P., Petkovi'c, A., and L.Milo`sevi'c. (2015). Methodology for route optimization for solid waste collection and transportation in urban areas. Working and Living Environmental Protection, 12(2), 187-197.

Sallem, R., and Rouis, M.J. (2017). Optimization of household waste collection routes using GIS: Case study of El Bousten District, Commune of Sfax , Tunisia. Current World Environment, 12(1), 53-60.

Sulemana, A., Donkor, E.A., Forkuo, E.K., and Oduro-Kwarteng, S. (2019). Effect of optimal routing on travel distance, travel time and fuel consumption of waste collection trucks. Management of Environmental Quality, 30(4), https://doi.org/10.1108/MEQ-07-2018-0134

Sulemana, A., Donkor, E. A., Forkuo, E. K., and Oduro-kwarteng, S. (2018). Optimal routing of solid waste collection trucks: A review of methods, 2018. https://doi.org/10.1155/2018/4586376

Tavares, G., Zsigraiova, Z., Semiao, V., and Carvalho, M. G. (2009). Optimisation of MSW collection routes for minimum fuel consumption using 3D GIS modelling. Waste Management, 29(3), 1176-1185. https://doi.org/10.1016/j.wasman.2008.07.013

Tchobanoglous, G., Theisen, H., and Vigil, S. A. (1993). Integrated Solid Waste Management. (B. J. Clark \& J. M. Morriss, Eds.) (International). New York: McGraw-Hill, Inc.

Zsigraiova, Z., Semiao, V., \& Beijoco, F. (2013). Operation costs and pollutant emissions reduction by definition of new collection scheduling and optimization of MSW collection routes using GIS. The case study of Barreiro, Portugal. Waste management, 33(4), 793-806. 